\title{
福建省戴云山野生哺乳动物和鸟类红外相机监测
}

\author{
林开粶 ${ }^{1,2}$ 徐建国 ${ }^{2}$ 李文周 ${ }^{2}$ 黄雅琼 $^{2}$ 陈 斌 $^{2}$ 郭进辉 $^{1^{*}}$ \\ 1 (武夷学院旅游学院, 福建武夷山 354300) \\ 2 (福建戴云山国家级自然保护区管理局, 福建德化 362500)
}

摘要: 2017年2月至2018年3月, 我们在福建省德化县戴云山国家级自然保护区和德化石牛山森林公园内设置红外 相机监测位点 60 个, 调查戴云山地区野生哺乳动物和鸟类生物多样性。本次调查累计 19,924 个相机工作日, 拍摄到 独立有效照片3,499张, 可准确鉴定哺乳动物4目10科17属18种, 鸟类5目11科21属24种, 家畜3种。其中, 国家I级重 点保护野生动物 2 种, 国家II级重点保护野生动物5种, 且白颈长尾雉(Syrmaticus ellioti)为戴云山自然保护区新记 录种。在野生哺乳动物中, 相对多度指数最高的前 5 种依次为小麇(Muntiacus reevesi)、野猪(Sus scrofa)、赤鹿 (Muntiacus vaginalis)、赤腹松鼠(Callosciurus erythraeus)、猪獾(Arctonyx collaris); 在岛类中, 相对多度指数最高的

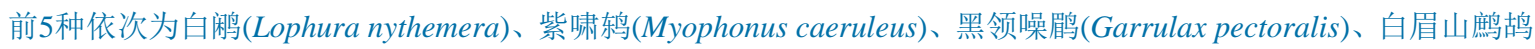
(Arborophila gingica)、灰胸竹鸡(Bambusicola thoracica)。此外，红外相机还拍摄到大量的家畜及人类活动照片，显 示区内存在较强的人为活动干扰。本次调查结果提供了较为全面的戴云山区哺乳动物和鸟类的本底信息, 填补了 闽中地区大中型哺乳动物观测的空白, 为后续的保护管理和长期监测工作建立了基础。

关键词: 野生动物监测; 石牛山森林公园; 戴云山国家级自然保护区; 相对多度指数

\section{Camera-trapping survey of wild mammals and birds in Daiyunshan, Fujian Province}

Kaimiao Lin ${ }^{1,2}$, Jianguo $\mathrm{Xu}^{2}$, Wenzhou $\mathrm{Li}^{2}$, Yaqiong Huang ${ }^{2}$, Bin Chen ${ }^{2}$, Jinhui Guo ${ }^{1 *}$

1 Department of Tourism Management College, Wuyi University, Wuyishan, Fujian 354300

2 Daiyunshan National Nature Reserve Administration, Dehua, Fujian 362500

\begin{abstract}
To investigate the biodiversity of wild mammals and birds in Daiyunshan National Nature Reserve and Shiniushan Forest Park (located in Dehua County, Fujian Province), 60 camera-traps were established and monitored from February 2017 to March 2018. A total of 3,499 independent photographs were collected with a sampling effort of 19,924 camera-days. This effort identified 18 wild mammal species belonging to 4 orders, 10 families, and 17 genera; 24 wild bird species belonging to 5 orders, 11 families and 21 genera; and 3 domestic animal species. Two of the species are listed as Class I Nationally Protected Wildlife, and 5 species are listed as Class II. One new species, Syrmaticus ellioti, was recorded at the Daiyunshan National Nature Reserve. Based on the relative abundance index, the five most abundant wild mammal species are Muntiacus reevesi, Sus scrofa, Muntiacus vaginalis, Callosciurus erythraeus, Arctonyx collaris, and the five most abundant bird species are Lophura nythemera, Myophonus caeruleus, Garrulax pectoralis, Arborophila gingica, Bambusicola thoracica. In addition, the detection rates of poultry, livestock and local villagers were rather high, which indicates high levels of anthropogenic disturbance across the study area. The results of this study provide a comprehensive baseline of the wild mammals and birds in the Daiyunshan and Shiniushan areas, fill the gaps in the observations of large and medium-sized mammals in central Fujian Province, and establish the basis for follow-up protection management and long-term monitoring.
\end{abstract}

Key words: wildlife monitoring; Shiniushan Forest Park; Daiyunshan National Nature Reserve; relative abundance index 
戴云山脉为福建第二大山脉, 中段位于德化县 境内, 以戴云山为主峰, 向四周倾斜, 呈层状逐级 下降, 最高海拔 $1,856 \mathrm{~m}$, 最低海拔 $650 \mathrm{~m}$, 垂直海 拔梯度大，气候与植被垂直变化明显。戴云山区主 峰周边建有福建戴云山国家级自然保护区和德化 石牛山森林公园两个自然保护地, 拥有丰富的野生 动物资源，是该区重要的生物多样性基因库。自 1985年戴云山国家级自然保护区建立以来, 保护区 先后多次对区内野生动物资源进行调查，2003年出 版的《福建戴云山自然保护区综合科学考察报告》 中记录该区共有哺乳动物 8 目 21 科 58 种，鸟类17目 45科194种(林鹏，2003), 为戴云山山脉闽中地区野 生动物监测奠定了基础。2016年保护区夏季鸟类样 线调查共发现鸟类29科22属72种, 其中14种为保护 区新记录种(林开沝等, 2017)。然而, 受到调查手段 等限制, 一些物种记录并不十分准确, 历史记录数 据不能完全反映该区域当前动物资源的现状。尤其 是随着人为活动对动物栖息环境的破坏以及气候 变化, 一些20世纪80年代以前记录的物种如金钱豹 (Panthera pardus)、华南虎(P. tigris huananensis), 及 2003 年科考报告中记录的物种如云豹 (Neofelis nebulosa)、穿山甲 (Manis pentadactyla)等，在本区域 内可能已局域灭绝。

红外相机调查技术具有“准确性、长期性、非 损伤性”等优点, 已成为野生动物本底资源调查和 生物多样性监测的重要手段(李慦等, 2014)。本研 究 于2017年2月至2018年3月，对福建戴云山国家级自 然保护区和德化石牛山森林公园内的野生哺乳动 物和鸟类开展了为期 1 年的红外相机调查, 以了解 该区野生动物资源现状, 掌握区内大中型哺乳动物 与地面活动鸟类的种类、相对多度与分布, 为该区 域大中型哺乳动物与地栖鸟类的研究和管理提供 本底资料, 填补闽中地区这两个野生动物类群观测 的空白。

\section{研究方法}

\section{1 研究区域概况}

在戴云山山脉中段戴云山区内, 选择戴云山国 家级自然保护区(以下简称戴云山保护区)和德化石 牛山森林公园两个区域开展野外红外相机监测。戴 云山保护区总面积为 $134.72 \mathrm{~km}^{2}$, 范围在 $118^{\circ} 05^{\prime} 22^{\prime \prime}-$ $118^{\circ} 20^{\prime} 15^{\prime \prime} \mathrm{E}, 25^{\circ} 38^{\prime} 07^{\prime \prime}-25^{\circ} 43^{\prime} 40^{\prime \prime} \mathrm{N}$ 之间, 海拔跨
度650-1,856 m; 石牛山森林公园面积 $86.82 \mathrm{~km}^{2}$, 主 峰位于水口镇, 海拔跨度300-1,782 m, 地理位置介 于 $118^{\circ} 24^{\prime} 3.3^{\prime \prime}-118^{\circ} 28^{\prime} 40^{\prime \prime}$ E, $25^{\circ} 36^{\prime} 59^{\prime \prime}-25^{\circ} 40^{\prime} 50^{\prime \prime} \mathrm{N}$ 之间。戴云山区地处亚热带海洋性季风气候带, 是 东南沿海典型的山地森林生态系统，植被类型为亚 热带常绿硬叶林、亚热带常绿阔叶林和大陆东南沿 海分布最南端、面积最大、保存最完好的黄山松(Pinus taiwanensis)林, 是福建省重要的生物多样性基因 库、水源涵养区、生态安全屏障和珍稀野生动植物 的生物安全岛屿, 对于福建省中部生物多样性保 护、生态安全保障、水源涵养、调节气候、净化空 气、科研教学实习等方面具有重要意义(林鹏, 2003)。

\section{2 红外相机布设方案}

在戴云山保护区设置 2 个观测样地, 石牛山森 林公园内设置1个样地。每个样地面积 $20 \mathrm{~km}^{2}$ (图1), 划分成 20 个 $1 \mathrm{~km} \times 1 \mathrm{~km}$ 的网格。在每个网格中心区 域选择合适位置放置1台红外相机，相邻网格的两 台相机间距不少于 $500 \mathrm{~m}$ 。共布设60台红外相机，型 号为猎科LTL 6511。戴云山保护区、石牛山森林公 园布设的调查点位海拔跨度分别为765-1,630 m、 649-1,355 m, 基本涵盖了戴云山脉中部不同生境, 包括常绿阔叶林、落叶阔叶林、竹林、针阔混交林、 针叶林、草甸。

红外相机固定于粗细合适的树干上，距离地面 高度约 $60 \mathrm{~cm}$ 。对每台相机进行定位和编号, 同时记 录生境信息。相机镜头与地面平行, 避免阳光直射 镜头。相机设置为 $24 \mathrm{~h} 工$ 作模式，拍摄时间间隔为 $15 \mathrm{~s}$ ，灵敏度设为“中”。每台相机配置南孚 5 号碱性 电池12节, SCAN 32 G 储存卡1张。电池、卡每3个月 更换 1 次, 下载回收数据; 如果发现不工作或存储 卡已经写满的相机，立即更换，同时清理相机视场 内的杂草、枯枝等。监测研究时间为2017年2月至 2018年3月，期间共收集照片4次。

\section{3 数据整理与分析}

整理红外相机所拍摄到的哺乳动物和鸟类照 片并进行物种鉴定。哺乳动物的分类体系参考《中 国哺乳动物多样性(第2版)》(蒋志刚等, 2017)，鸟类 的分类体系参考《中国鸟类分类与分布名录(第三 版)》 (郑光美, 2017)。夜晚拍到的鼠科动物由于个 体较小, 不易辨识, 在计算相对多度指数(relative abundance index, RAI)时统一归为鼠类。定义同一只 (群)动物在同一相机位点间隔3 $\mathrm{min}$ 内连续拍摄的 


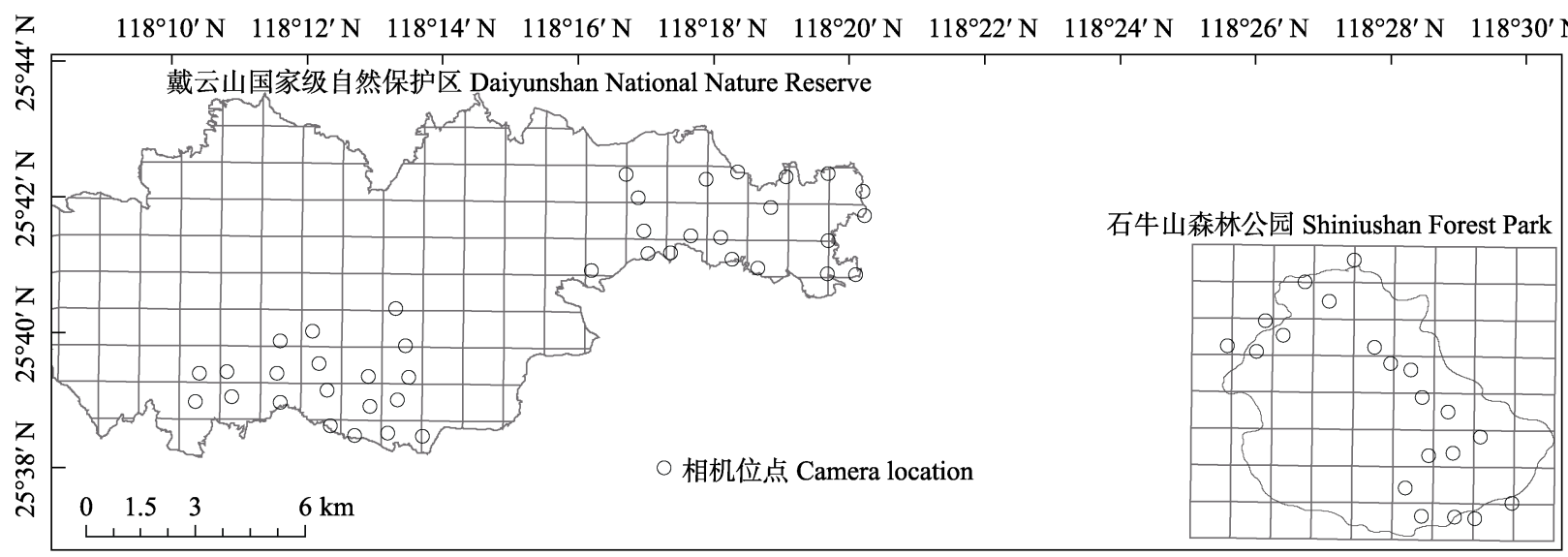

图1 福建戴云山国家级自然保护区与石牛山森林公园2017-2018年红外相机监测位点分布图

Fig. 1 Camera-trapping survey stations in Daiyunshan National Nature Reserve and Shiniushan Forest Park of Fujian Province during 2017-2018.

照片作为1张独立有效照片。根据独立有效照片计 算相对多度指数(李勤等, 2013; 施小刚等, 2017):

$$
\mathrm{RAI}=A_{i} / N \times 1000
$$

其中, $A_{i}$ 代表第 $i$ 类 $(i=1,2, \cdots)$ 动物出现的有效照片 数, $N$ 为总有效相机工作日。

\section{2 结果}

红外相机一年内累计监测19,924个相机工作日, 共获得有效照片 25,286 张, 其中鸟类4,216张、哺乳 动物 10,245 张、家畜10,825张。独立有效照片3,499 张, 占总有效照片数的 $13.83 \%$, 其中野生鸟类独立 有效照片 1,040 张，占鸟类总有效照片数的 $24.67 \%$; 野生哺乳动物 2,054 张, 占野生哺乳动物总有效照 片数的 $20.04 \%$ 。获得可准确鉴定的野生动物 42 种, 隶属9目21科38属, 其中鸟类5目11科21属24种, 哺 乳动物4目 10 科17属18种。属于国家I级重点保护的 野生动物 2 种, 即黄腹角雉(Tragopan caboti)、白颈 长尾雉(Syrmaticus ellioti); II级重点保护的野生动物 5 种, 即中华瓺羚(Capricornis milneedwardsii)、小灵 猫(Viverricula indica)、黄喉貂(Martes flavigula)、白 㭤(Lophura nythemera)、褐翅鸦鹃(Centropus sinensis) (附录1, 附录2)。

相对多度指数排名前 5 的鸟类依次为白㜀(RAI = 33.13)、紫啸斩(Myophonus caeruleus, RAI = 7.28)、 黑领噪鿬 (Garrulax pectoralis, RAI = 4.97)、白眉山 鹈鸪(Arborophila gingica, RAI = 2.71)、灰胸竹鸡 (Bambusicola thoracica, RAI = 0.70)。国家I级重点保 护野生动物黄腹角雉相对多度指数在鸟类中排名
第6位 $(\mathrm{RAI}=0.55)$, 白颈长尾雉最低 $(\mathrm{RAI}=0.05)$ (附录1)。野生哺乳动物相对多度指数排名前 5 的物 种分别为小鹿(Muntiacus reevesi, RAI = 28.81)、野 猪 (Sus scrofa，RAI = 18.42)、赤鹿 (Muntiacus vaginalis, RAI = 14.71)、赤腹松鼠 (Callosciurus erythraeus, RAI = 9.94)、猪獾 $($ Arctonyx collaris, RAI $=4.12)$ 。中华鬛羚 $(\mathrm{RAI}=0.35)$ 、小灵猫 $(\mathrm{RAI}=0.30)$ 相对多度指数较低(附录1, 附录 2 )。

\section{3 讨论}

通过一年多的红外相机监测，拍摄到大量的野 生动物照片和视频(附录3), 可鉴定哺乳动物 18 种、 鸟类24种, 分别占戴云山保护区及周边地区已记录 哺乳动物的 $31.03 \%$ (林鹏，2003)和鸟类的 $11.53 \%$ (林开沝等, 2017)。红外相机拍摄到大量小型啮齿类 动物, 如鼠类, 它们主要在夜间活动, 且动作迅速, 体型较小, 外形相似, 红外相机很难捕捉到可辨认 物种的清晰照片，本次调查能鉴别的只有板齿鼠 (Bandicota indica)和白腹巨鼠(Leopoldmys edwardsi) 两种。红外相机监测适合于拍摄地面活动的哺乳动 物和林下鸟类, 对营洞穴生活的小型哺乳动物和体 型较小的林冠活动鸟类来说则不是一种有效的调 查手段(李佳等, 2018)。与保护区历史记录鸟类名录 相比, 本次调查拍摄到的白颈长尾雉是保护区新记 录种。开展鸟类多样性专项调查, 应该采用多种调 查方法如样线法来补充红外相机调查技术的不足。

对比戴云山保护区以往的记录(林鹏，2003)和 现存标本, 本次调查拍摄到的灵猫科动物中, 果子 
狸(Paguma larvata)较为常见，小灵猫拍到6次，历 史有记录的大灵猫(Viverra zibetha)没有拍到, 大灵 猫在20世纪80年代初已经十分稀少(王岐山, 1990)。 鼠科有猪獾、黄喉貂、鼠由獾(Melogale moschata)、 黄鼠(Mustela sibirica) 4种, 黄喉貂相对多度最低。 松鼠科有赤腹松鼠和倭花鼠(Tamiops maritimus), 历史记录的泊氏长吻松鼠(Dremomys pernyi)(林鹏, 2003)没有拍到。该地区历史上分布的一些重要珍稀 物种如豹猫 (Prionailurus bengalensis)、金猫 (Catopuma temminckii)、云豹、金钱豹和华南虎等 也未拍摄到。结合保护区内当地居民的观察和保护 区近年来的样线调查记录, 这些物种目前种群状况 不明, 可能种群密度极低, 或有些物种如华南虎可 能已局域绝灭, 其主要原因可归结于该地区栖息地 片断化、丧失以及近期历史上的过度猎杀。另外, 由 于本次调查主要集中在戴云山区的南部和东部, 北 部和西部的红外相机监测点较少, 且监测时间较短, 是否仍然存在云豹等大型哺乳动物还需要更多的 调查验证。在本次调查中, 有蹄类哺乳动物如小鹿、 赤鹿和野猪等在较多位点被监测到, 可能间接佐证 该区缺乏大型食肉哺乳动物来调控食草动物种群 数量(Gordon et al, 2015)。

本次在戴云山区拍摄到 3 种鹿科动物: 小鹿、赤 鹿和毛冠鹿(Elaphodus cephalophus), 这与《福建哺 乳动物种类名录》(周冬良, 1997)和戴云山保护区以 往的记录(林鹏，2003)相一致。同时本次调查发现3 种鹿科动物相对多度指数大小差异较大, 依次为小 鹿 > 赤鹿 > 毛冠鹿, 在福建省其他地区还未有三 种动物多度指数大小差异的相关报道, 是否别的地 区也呈现类似规律还有待进一步研究。但是从全国 红外相机哺乳动物调查结果来看, 三者同时出现在 同一地区的情况较少, 仅见广东南岭国家级自然保 护区的报道(蔡玉生等, 2016), 且毛冠鹿数量稀少。 毛冠鹿在中国分布范围较为广泛, 最适生存区在亚 热带范围内(盛和林和陆厚基, 1982), 但最北可以到 宁夏六盘山(高惠等, 2017); 而赤鹿主要分布于印 度、东南亚和我国热带及南亚热带地区(单祥年等, 2004); 小鹿主要分布在我国秦岭以南、云南哀牢山 以北地区，属于中亚热带至北亚热带范围(鲁庆彬 等, 2007)。同域内鹿科动物稳定共存可能受到栖息 地环境、食性、生理、活动时间和体型以及种间关 系等因素的影响(杨帆等, 2018)。戴云 山位于中亚热
带和南亚热带的交界线, 植物多样性丰富、海拔高 度差较大, 为 3 种动物同域共存提供了基础。赤鹿和 小鹿的栖息地生境选择具有一定的重叠性, 一般选 择在低丘乔木密度适中、灌从密度大和郁闭度适中 的生境(白德凤等, 2018)。两者在本区空间分布上的 大量重叠表明它们可能在空间和时间尺度上对食 性、生境利用的细微区别。尽管毛冠鹿的食性和小 鹿甚为相似(盛和林和陆厚基, 1982), 但毛冠鹿主要 栖息于较高的丘陵, 在空间上与赤鹿和小鹿重叠性 较小(Chen \& Hu, 2012), 戴云山较大的海拔差能够 为毛冠鹿提供较为广泛的活动空间和食物来源, 降 低与赤鹿和小鹿在食物和空间上的竞争。但是受食 物资源、温度和环境等影响, 毛冠鹿季节性的海拔 梯度迁移可能造成与赤鹿和小鹿生态位的重叠; 而 且戴云山低海拔人为活动的影响造成的小鹿、赤鹿 栖息地破坏和片断化有可能使其向更高海拔迁移， 这将加剧3种动物的种间竞争, 造成种群数量的波 动。随着全球气候变化和人为活动等多因素的影响, 需要进一步开展小鹿、赤鹿和毛冠鹿的种群分布、 变化和动态迁移等多方面的研究(徐海根, 2018) ${ }^{\circledR}$ 。

中华鬏羚是国家II级重点保护野生动物, 主要 分布在树林茂密、地势险峻的地方, 随着多年来栖 息地的破坏和人类的滥捕滥杀, 野生种已经较难发 现。本次调查共有 5 个相机位点拍摄到中华瓺羚, 其 中4个位点位于石牛山森林公园样区, 1 个位点在戴 云山国家级自然保护区样区, 表明该动物在德化戴 云山区分布范围较为狭窄。另外石牛山森林公园样 区还拍摄到黄腹角雉、白颈长尾雉两种国家I级保护 动物, 由此可见戴云山区较多的珍稀保护动物并未 包含在国家级自然保护区之内。因此, 石牛山森林 公园中珍稀濒危物种的栖息地保护极为重要, 然而 近年来该区所在政府为了发展县域旅游, 在其周边 地区开展索道、玻璃栈道等旅游设施建设开发, 导 致野生动物栖息地的破碎化, 而人为旅游活动极大 可能会造成野生保护动物的消减或者灭绝。鉴于戴 云山区区位的特殊性及对气候变化的敏感性, 未来 应该积极推动戴云山国家公园试点和绿色发展, 探 讨生态旅游和物种保护并存机制, 实现野生动物在 环境变化和人为影响下的永续生存。

(1) 徐海根 (2018) 2017 年全国生物多样性观测报告. 见: 生物多样性 绿皮书, 52-53 页. 南京环境科学研究所, 南京. 
人为活动对野生哺乳动物的影响较大, 从拍摄 到的照片分析来看，戴云山区内周边社区存在家畜 如牛、羊、狗等进入保护区内的现象, 较严重破坏 野生动物栖息环境并争夺食物, 另外打猎、旅游、 挖笋等人为活动较多, 需要加强进山人员的管理和 监测。因此，如何减少当地社区居民、家畜、家犬 等活动对野生动物产生的直接或间接影响, 值得保 护区管理人员深入思索。本研究所获得的数据和信 息较为全面地反映了戴云山区哺乳动物和鸟类的 本底信息, 为后续的保护管理和长期监测提供了数 据支持和指导。目前, 戴云山区森林红外相机监测 仍然在进行中, 更多的深入研究有待获取更多的后 续监测数据。

致谢: 本研究野外调查得到福建戴云山国家级自然 保护区管理局陈文伟、蔡孝星、陈亚婷、林有星等 同志的支持，在此一并致谢!

\section{参考文献}

Bai DF, Chen Y, Li JS, Tao Q, Wang LF, Piao Y, Shi K (2018) Mammal diversity in Shangyong Nature Reserve, Xishuangbanna, Yunnan Province. Biodiversity Science, 26, 75-78. (in Chinese with English abstract) [白德风, 陈颖, 李俊松, 陶庆, 王利繁, 飘优, 时坤 (2018) 西双版纳尚勇自然保 护区哺乳动物物种多样性. 生物多样性, 26, 75-78.]

Cai YS, Gong YN, Lu XL, Xiao ZS, Wang XC (2016) Camera trap survey of mammal diversity in Nanling Forests. Ecological Science, 35(2), 57-61. (in Chinese with English abstract) [蔡玉生, 龚粤宁, 卢学理, 肖治术, 王新财 (2016) 南岭森林哺乳动物多样性的红外相机监测. 生态 科学, 35(2), 57-61.]

Chen W, Hu JC (2012) Seasonal differences in microhabitat use by tufted deer (Elaphodus cephalophus) in Tangjiahe Nature Reserve. Acta Theriologica Sinica, 32, 188-192.

Gao H, Ma ZQ, Teng LW, Liu ZS, Zhao C, Sun YJ, Guo ZH (2017) Tufted deer (Elaphodus cephalophus) was discovered in the Liupan Mountain National Nature Reserve, Ningxia Hui Autonomous Region, China. Chinese Journal of Zoology, 52, 1066-1068. (in Chinese with English abstract) [高惠, 马忠其, 滕丽微, 刘振生, 赵唱, 孙玉姣, 郭志宏 (2017) 宁夏回族自治区六盘山国家级自然保护区发现毛 冠鹿. 动物学杂志, 52, 1066-1068.]

Gordon CE, Feit A, Grüber J, Letnic M (2015) Mesopredator suppression by an apex predator alleviates the risk of predation perceived by small prey. Proceedings of the Royal Society B: Biological Sciences, 282, 1-8.

Jiang ZG, Liu SY, Wu Y, Jiang XL, Zhou KY (2017) China’s mammal diversity (2nd edition). Biodiversity Science, 25, 886-895. (in Chinese with English abstract) [蒋志刚, 刘少 英, 吴毅, 蒋学龙, 周开亚 (2017) 中国哺乳动物多样性 (第2版). 生物多样性, 25, 886-895.]

Li J, Liu F, Ye LX, Liu SL, Peng H, Li DQ (2018) Camera-trapping survey of the diversity of mammals and birds in Fengyang Mountain of Zhejiang Province, China. Acta Theriologica Sinica, 38, 95-103. (in Chinese with English abstract) [李佳, 刘芳, 叶立新, 刘胜龙, 彭辉, 李 迪强 (2018) 利用红外相机调查浙江省凤阳山兽类和鸟 类多样性. 兽类学报, 38, 95-103.]

Li Q, Wu JG, Kou XJ, Feng LM (2013) Applications of camera trap in wildlife population ecology. Chinese Journal of Applied Ecology, 24, 947-955. (in Chinese with English abstract) [李勤, 邬建国, 寇晓军, 冯利民 (2013) 相机陷 阱在野生动物种群生态学中的应用. 应用生态学报, 24, 947-955.]

Li S, Wang DJ, Xiao ZS, Li XH, Wang TM, Feng LM, Wang $Y$ (2014) Camera-trapping in wildlife research and conservation in China: Review and outlook. Biodiversity Science, 22, 685-695. (in Chinese with English abstract) [李 晟, 王大军, 肖治术, 李欣海, 王天明, 冯利民, 王云 (2014) 红外相机技术在我国野生动物研究与保护中的应 用与前景. 生物多样性, 22, 685-695.]

Lin KM, Huang YQ, Chen WW, Xu JG, Hong LB, Chen B (2017) Community structure and biodiversity of summer birds in Dehua County. Inner Mongolia Forestry Investigation and Design, 40(2), 51-55. (in Chinese with English abstract) [林开沝, 黄雅琼, 陈文伟, 徐建国, 洪丽 涁, 陈斌 (2017) 德化县夏季鸟类群落结构及多样性调 查. 内蒙古林业调查设计, 40(2), 51-55.]

Lin P (2003) Comprehensive Scientific Investigation Report of Daiyunshan Nature Reserve in Fujian. Xiamen University Press, Xiamen. (in Chinese) [林鹏 (2003) 福建戴云山自 然保护区综合科学考察报告. 厦门大学出版社, 厦门.]

Lu QB, Yu JA, Gao X, Yang XY, Zhou Q, Zhang LB, Zhang SY (2007) Winter habitat selection of Reeves' muntjac and wild boars in the Qingliangfeng Mountains. Acta Theriologica Sinica, 27, 45-52. (in Chinese with English abstract) [鲁庆涁, 于江傲, 高欣, 杨仙玉, 周圻, 张良斌, 章叔岩 (2007) 冬季清凉峰山区小鹿和野猪的生境选择 及差异. 兽类学报, 27, 45-52.]

Shan XN, Shi YF, Zhang HJ, Xu CH, Li J, Zheng AL (2004) mtDNA sequences variability of Munliacus reevesi, $M$. muntjak and $M$. crinifrons as well as the related phylogenetic relationship. Chinese Journal of Zoology, 39, 35-39. (in Chinese with English abstract) [单祥年, 施燕峰, 张海军, 徐春宏, 李健, 郑爱玲 (2004) 小鹿、赤鹿、黑 鹿mtDNA序列变异性及反映的进化关系. 动物学杂志, 39, 35-39.]

Sheng HL, Lu HJ (1982) Distribution, habits and resource status of the tufted deer (Elaphodus cepholophus). Acta Zoologica Sinica, 28, 307-311. (in Chinese with English 
abstract) [盛和林, 陆厚基 (1982) 毛冠鹿的分布、资源和 习性. 动物学报, 28, 307-311.]

Shi XG, Hu Q, Li JQ, Tang Z, Yang J, Li WJ, Shen XL, Li S (2017) Camera-trapping surveys of the mammal and bird diversity in Wolong National Nature Reserve, Sichuan Province. Biodiversity Science, 25, 1131-1136. (in Chinese with English abstract) [施小刚, 胡强, 李佳琦, 唐卓, 杨 建, 李文静, 申小莉, 李晟 (2017) 利用红外相机调查四 川卧龙国家级自然保护区乌兽多样性. 生物多样性, 25, 1131-1136.]

Wang QS (1990) The Mammal Fauna of Anhui. Anhui Science and Technology Publishing House, Hefei. (in Chinese) [王 岐山 (1990) 安徽兽类志. 安徽科学技术出版社, 合肥.]

Yang F, Hu SX, Wang JJ, Guo K, Jiang GS (2018) Spatial interaction among free-ranging ungulates by season at the microhabitat scale. Chinese Journal of Wildlife, 39, 224-230. (in Chinese with English abstract) [杨帆, 胡素贤, 王晶晶, 郭楷, 姜广顺 (2018) 微生境尺度下有蹄类动物 空间季节利用互作关系研究. 野生动物学报, 39, 224-230.]

Zheng GM (2017) A List of Classification and Distribution of Birds in China, 3rd edn. Science Press, Beijing. (in Chinese) [郑光美 (2017) 中国鸟类分类与分布名录(第三版). 科 学出版社, 北京.]

Zhou DL (1997) A list of mammal species from Fujian, China. Wuyi Science Journal, 13, 256-261. (in Chinese with English abstract) [周冬良 (1997) 福建哺乳动物种类名录. 武夷科学, 13, 256-261.]

(特邀责任编委: 李晟 责任编辑: 间文杰)

\section{附录 Supplementary Material}

\section{附录1 戴云山森林红外相机记录的野生哺乳动物和鸟类名录}

Appendix 1 Wild mammals and birds recorded by camera trapping in Daiyunshan Forests http://www.biodiversity-science.net/fileup/PDF/2018216-1.pdf

附录2 戴云山森林红外相机拍摄的野生哺乳动物和鸟类物种坐标记录

Appendix 2 Coordinate record of wild mammals and birds recorded by camera trapping in Daiyunshan Forests http://www.biodiversity-science.net/fileup/PDF/2018216-2.xlsx

附录3 戴云山森林红外相机拍摄到的重要哺乳动物和鸟类照片

Appendix 3 Important mammals and birds recorded by camera trapping in Daiyunshan Forests http://www.biodiversity-science.net/fileup/PDF/2018216-3.pdf 
林开丞, 徐建国, 李文周, 黄雅琼, 陈斌, 郭进辉. 福建省戴云山野生哺乳动物和鸟类红外相机监测. 生物 多样性, 2018, 26 (12): 1332-1337.

http://www.biodiversity-science.net/CN/10.17520/biods.2018216

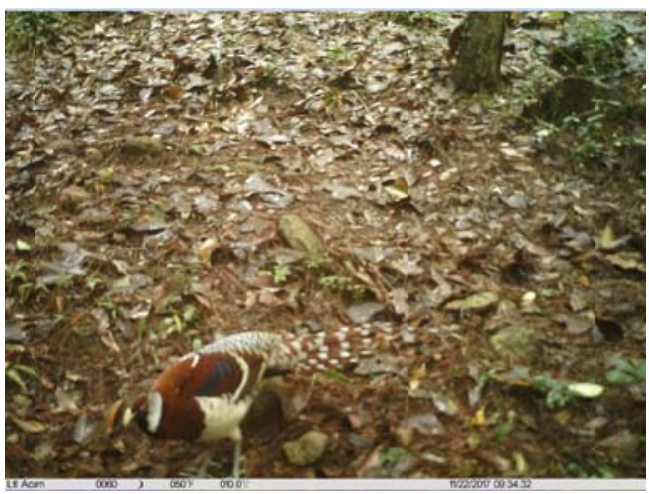

白颈长尾雉 Syrmaticus ellioti

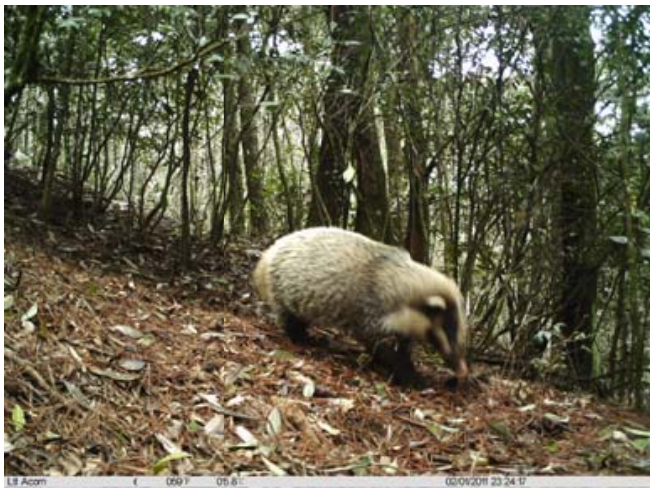

猪獾 Arctonyx collaris

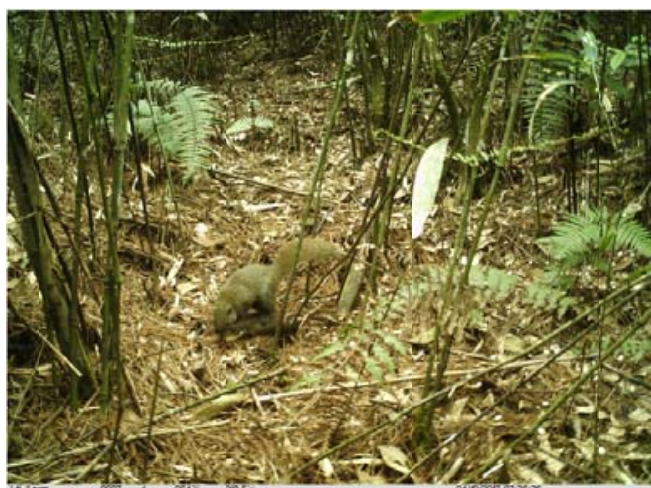

赤腹松鼠 Callosciurus erythraeus

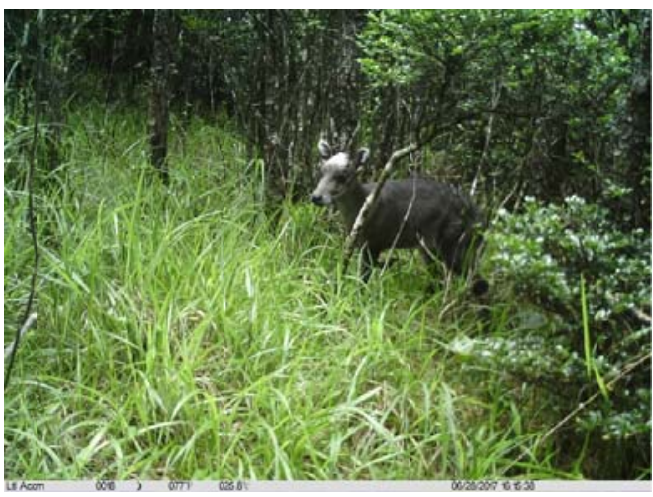

毛冠鹿 Elaphodus cephalophus

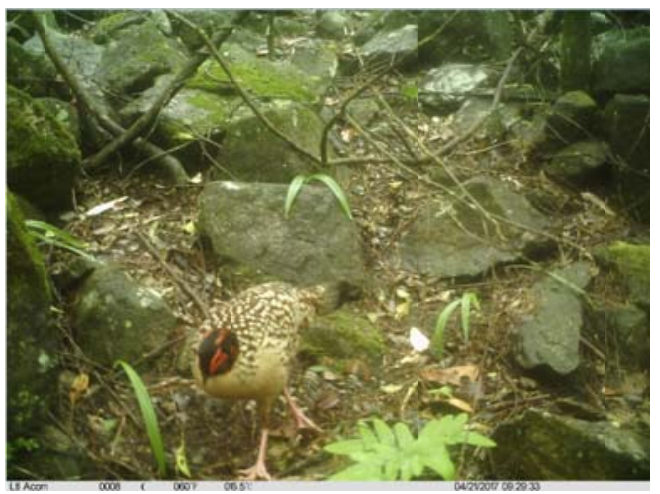

黄腹角雉 Tragopan caboti

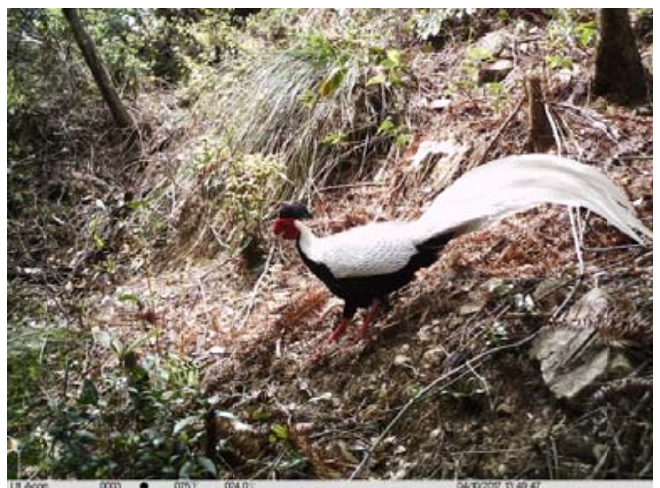

白闲 Lophura nythemera

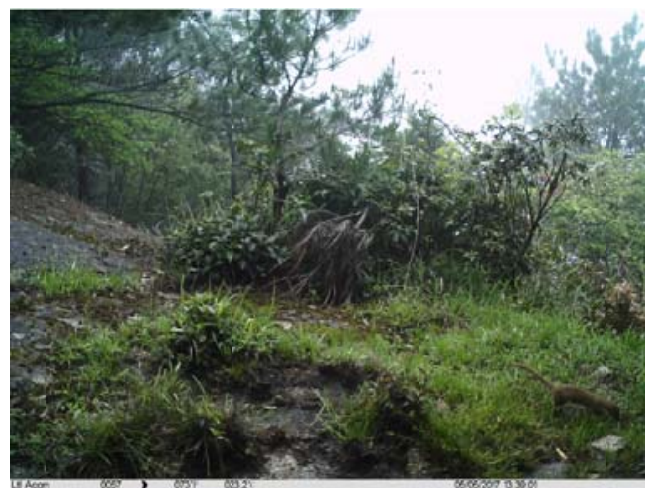

黄鼠由 Mustela sibirica

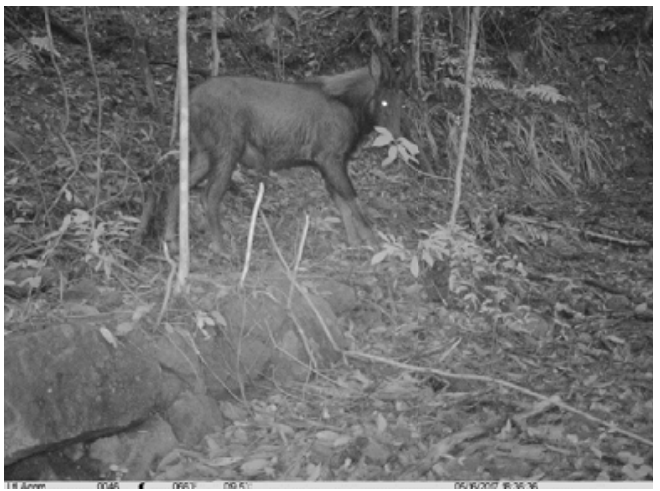

中华鬣羚 Capricornis milneedwardsii

附录3 戴云山森林红外相机拍摄到的重要哺乳动物和鸟类照片

Appendix 3 Important mammals and birds recorded by camera trapping in Daiyunshan Forests 
林开丞, 徐建国, 李文周, 黄雅琼, 陈斌, 郭进辉. 福建省戴云山野生哺乳动物和鸟类红外相机监测. 生物 多样性, 2018, 26 (12): 1332-1337.

http://www.biodiversity-science.net/CN/10.17520/biods.2018216

附录1 戴云山森林红外相机记录的野生哺乳动物和鸟类名录

Appendix 1 Wild mammals and birds recorded by camera trapping in Daiyunshan Forests

\begin{tabular}{lllll}
\hline 物种 & 保护等级 & 相机位点数 & 独立照片数 & 相对多度指数 \\
Species & Protection & Camera & Independent & Relative \\
& level & location & photos & abundance index \\
\hline
\end{tabular}

兽类 Mammals

兔形目 Lagomorpha

兔科 Leporidae

兔属 Lepus

华南兔 Lepus sinensis

4

5

0.25

啮齿目 Rodentia

松鼠科 Sciuridae

丽松鼠属 Callosciurus

赤腹松鼠 Callosciurus erythraeus

35

198

9.94

花松鼠属 Tamiops

倭花鼠 Tamiops maritimus

3

4

0.20

鼠科 Muridae*

33

397

19.93

板齿鼠属 Bandicota

板齿鼠 Bandicota indica

小泡鼠属 Leopoldmys

白腹巨鼠 Leopoldmys edwardsi

豪猪科 Hystricidae

豪猪属 Hystricidae

豪猪 Hystricidae hodgsoni

2

7

0.35

食肉目 Carnivora

鼠由科 Mustelidae

猪獾属 Arctonyx

猪獾 Arctonyx collaris

23

82

4.12

貂属 Martes

黄喉貂 Martes flavigula

二级 1

3

0.15

鼠獾属 Melogale

鼠獾 Melogale moschata

8

25

1.25

鼠由属 Mustela

黄鼠 Mustela sibirica

4

31

1.56

獴科 Herpestidae

獴属 Herpestes

食蟹獴 Herpestes urva

11

28

1.41

灵猫科 Viverridae

果子狸属 Paguma

果子狸 Paguma larvata

36

23

1.15

小灵猫属 Viverricula

小灵猫 Viverricula indica

二级 4

6

0.30

偶蹄目 Artiodactyla

猪科 Suidae 
林开丞, 徐建国, 李文周, 黄雅琼, 陈斌, 郭进辉. 福建省戴云山野生哺乳动物和鸟类红外相机监测. 生物 多样性, 2018, 26 (12): 1332-1337.

http://www.biodiversity-science.net/CN/10.17520/biods.2018216

\begin{tabular}{|c|c|c|c|c|}
\hline $\begin{array}{l}\text { 物种 } \\
\text { Species }\end{array}$ & $\begin{array}{l}\text { 保护等级 } \\
\text { Protection } \\
\text { level }\end{array}$ & $\begin{array}{l}\text { 相机位点数 } \\
\text { Camera } \\
\text { location }\end{array}$ & $\begin{array}{l}\text { 独立照片数 } \\
\text { Independent } \\
\text { photos }\end{array}$ & $\begin{array}{l}\text { 相对多度指数 } \\
\text { Relative } \\
\text { abundance index }\end{array}$ \\
\hline \multicolumn{5}{|l|}{ 猪属 Sus } \\
\hline 野猪 Sus scrofa & & 40 & 367 & 18.42 \\
\hline \multicolumn{5}{|l|}{ 鹿科 Cervidae } \\
\hline 小鹿 Muntiacus reevesi & & 46 & 574 & 28.81 \\
\hline 赤鹿 Muntiacus vaginalis & & 40 & 293 & 14.71 \\
\hline \multicolumn{5}{|l|}{ 毛冠鹿属 Elaphodus } \\
\hline 毛冠鹿 Elaphodus cephalophus & & 1 & 4 & 0.20 \\
\hline $\begin{array}{l}\text { 牛科 Bovidae } \\
\text { 鬛羚属 Capricornis } \\
\text { 中华瓺羚 Capricornis milneedwardsii }\end{array}$ & 二级 & 5 & 7 & 0.35 \\
\hline \multicolumn{5}{|l|}{$\begin{array}{l}\text { 雉科 Phasianidae } \\
\text { 山麅鸪属 Arborophila }\end{array}$} \\
\hline \multicolumn{5}{|l|}{ 洞属 Lophura } \\
\hline \multicolumn{5}{|l|}{ 角雉属 Tragopan } \\
\hline \multicolumn{5}{|l|}{ 雉属 Phasianus } \\
\hline \multicolumn{5}{|l|}{ 长尾雉属 Syrmaticus } \\
\hline \multicolumn{5}{|l|}{ 竹鸡属 Bambusicola } \\
\hline 灰胸竹鸡 Bambusicola thoracica & & 3 & 14 & 0.70 \\
\hline $\begin{array}{l}\text { 冩形目 Piciformes } \\
\text { 豚木鸟科 Picidae } \\
\text { 绿啄木鸟属 Picus }\end{array}$ & & & & \\
\hline 灰头绿豚木鸟 Picus canus & & 3 & 3 & 0.15 \\
\hline \multicolumn{5}{|l|}{ 噪豚木鸟属 Blythipicus } \\
\hline 黄嘴栗豚木鸟 Blythipicus pyrrhotis & & 2 & 6 & 0.30 \\
\hline $\begin{array}{l}\text { 雀形目 Passeriformes } \\
\text { 玜科 Muscicapidae } \\
\text { 啸冻属 Myophonus }\end{array}$ & & & & \\
\hline 紫啸冻 Myophonus caeruleus & & 18 & 145 & 7.28 \\
\hline \multicolumn{5}{|l|}{ 鸲属 Tarsiger } \\
\hline 红胁蓝尾鸲 Tarsiger cyanurus & & 1 & 1 & 0.05 \\
\hline \multicolumn{5}{|l|}{ 冻科 Turdidae } \\
\hline 虎斑地冻 Zoothera dauma & & 7 & 11 & 0.55 \\
\hline
\end{tabular}


林开丞, 徐建国, 李文周, 黄雅琼, 陈斌, 郭进辉. 福建省戴云山野生哺乳动物和鸟类红外相机监测. 生物 多样性, 2018, 26 (12): 1332-1337.

http://www.biodiversity-science.net/CN/10.17520/biods.2018216

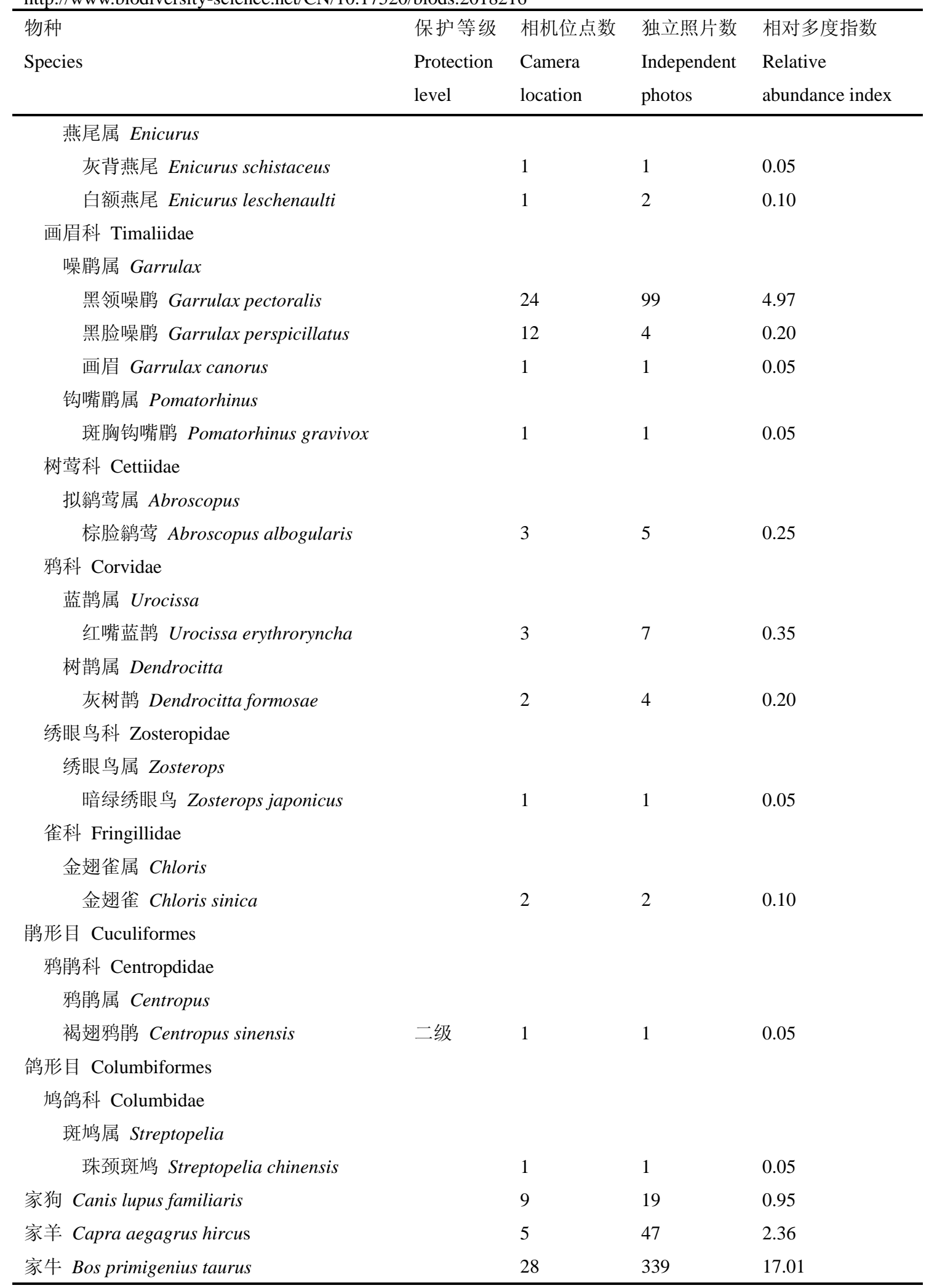

*鼠科动物难以鉴别, 计算时统归为一种 All rodents was classified as Muridae

保护等级参考《中国国家重点保护野生动物名录》The protection level refers to the National Catalogue of China's Key Protected Wildlife 